\title{
UNA NUEVA SUBESPECIE DE GENTIANA OVATILOBA (GENTIANACEAE)
}

\author{
Jose Angel Villarreal Quintanilla \\ Departamento de Botánica \\ Universidad Autónoma Agraria Antonio Narro \\ 25315 Buenavista, Saltillo, Coahuila
}

\section{RESUMEN}

Se propone a Gentiana ovatiloba Kusn. ssp. michoacana Villarreal como un nuevo taxon del centro de México. La población descrita aquí presenta los lóbulos del cáliz notablemente foliáceos y extendidos, hojas anchamente elípticas a ovadas y lóbulos de la corola más pequeños que la subespecie típica. Se incluye la ilustración correspondiente.

\section{ABSTRACT}

Gentiana ovatiloba Kusn. ssp. michoacana Villarreal is proposed as a new taxon from central Mexico. The population here described as a new subspecies is characterized by spreading, broadly foliaceous calyx lobes, broadly elliptic to ovate leaf blades and corolla lobes smaller than those of the typical subspecies. An illustration is presented.

Durante la preparación del manuscrito correspondiente a la familia Gentianaceae para la Flora del Bajío y de Regiones Adyacentes se encontró que los ejemplares de Gentiana ovatiloba colectados en Michoacán muestran significativas diferencias con la descripción de Pringle (1977) y con los demás especímenes conocidos de esta especie. Lo anterior nos lleva a proponer la categoría de subespecie para esta variante.

Gentiana ovatiloba Kusn. ssp. michoacana Villarreal, ssp. nov. Fig. 1.

Gentianae ovatilobae ssp. ovatilobae similis sed differt lobis calycis foliaceis patentibus, foliis late ellipticis ad ovatis et corollae lobis minoribus.

Planta perenne con raíz pivotante que da lugar a tallos tendidos de 10 a $20 \mathrm{~cm}$ de largo, delgados, de 0.6 a $1.0 \mathrm{~mm}$ de grueso, ligeramente alados, glabros a puberulentos, simples; hojas opuestas, pecíolos de 1 a $2 \mathrm{~mm}$ de largo, usualmente puberulentos, limbos extendidos, ampliamente elípticos a ovados, de 10 a $18 \mathrm{~mm}$ de largo y 6 a $12 \mathrm{~mm}$ de ancho, ápice obtuso a redondeado, base redondeada, decurrente en el pecíolo, borde entero, ligeramente engrosado, trinervados, glabros, delgados; flores solitarias o en cimas, terminales y axilares en la porción terminal del tallo; pedicelos de 5 a $10 \mathrm{~mm}$ de largo; cáliz campanulado, el tubo de 5 a $7 \mathrm{~mm}$ de largo, ápice truncado, lóbulos ampliamente elípticos a ovados, estrechos en la base, de 6 a $8 \mathrm{~mm}$ de largo, de 3 a $4 \mathrm{~mm}$ de ancho, 


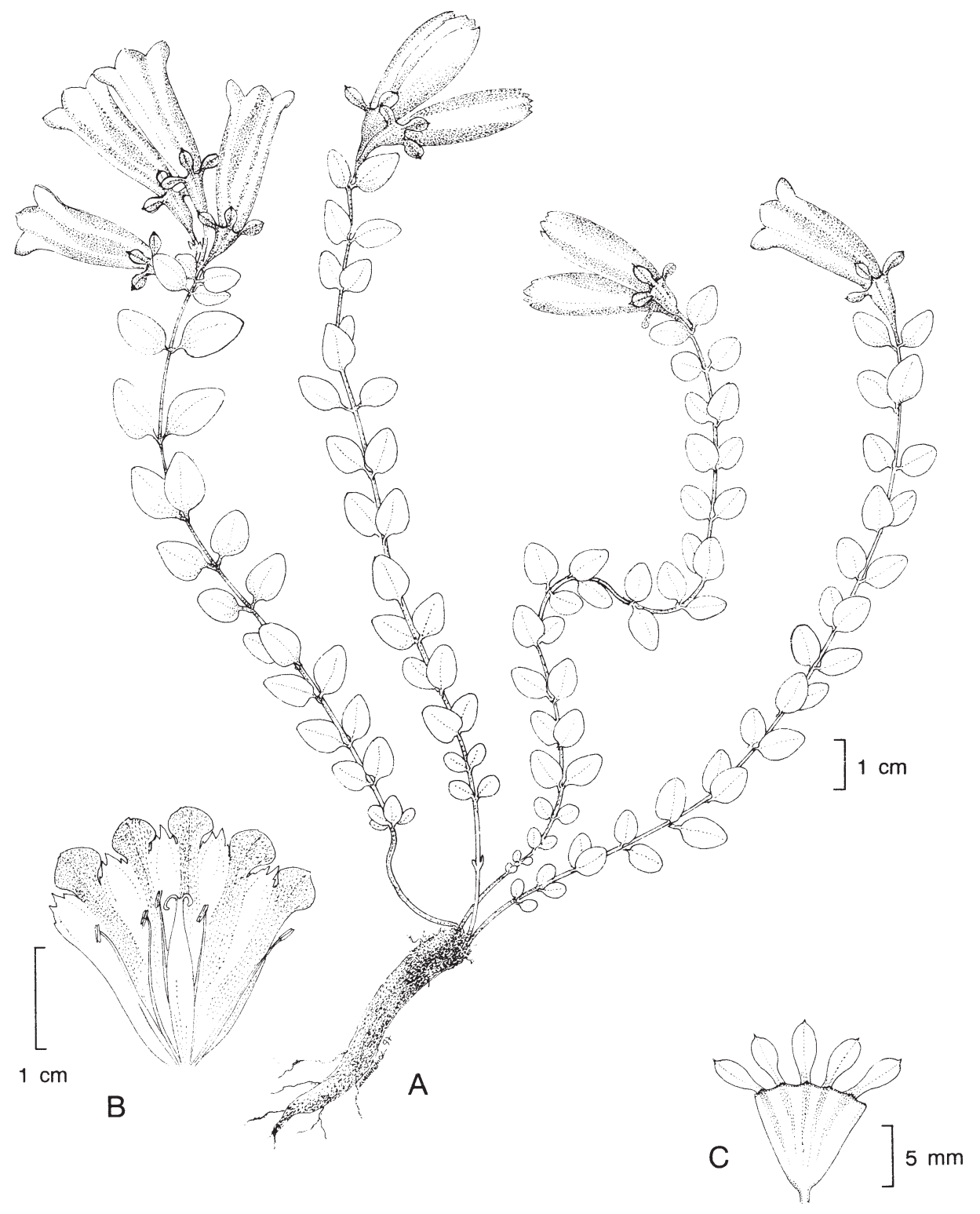

Fig. 1. Gentiana ovatiloba Kusn. ssp. michoacana Villarreal. A. planta completa; B. flor disecada; C. cáliz disecado. (Tomado del holotipo). 
extendidos; corola campanulada, de 2.5 a $3 \mathrm{~cm}$ de largo, morada con bandas de color blanco-crema en los apéndices interpetalinos, lóbulos ovados a oblatos, ligeramente apiculados, de 4 a $6 \mathrm{~mm}$ de largo y 4 a $6 \mathrm{~mm}$ de ancho, apéndices interpetalinos bicuspidados, de 1 a $2 \mathrm{~mm}$ de largo; estambres con filamentos soldados al tubo de la corola, la porción libre menor que la soldada, anteras de $3 \mathrm{~mm}$ de largo; pistilo estrechamente elipsoide, de $10 \mathrm{~mm}$ de largo, estilo corto, estigma bilobulado.

TIPO: México. Michoacán. Mpio. de Zinapécuaro, lado SE del Cerro San Andrés, 3330 m, bosque de Abies en pastizal, 9.XII.1988. M. J. Jasso 666 (Holotipo: MEXU, Isotipos: EBUM, IEB).

Material adicional examinado: Michoacán: Mpio. de Zinapécuaro, parte alta del Cerro San Andrés, 3430 m, pastizal con bosque de pino, 9.XII.1988. S. Zamudio y E. Pérez 7089 (IEB).

Gentiana ovatiloba se distribuye en las partes altas de las montañas del Eje Neovolcánico y de la Sierra Madre del Sur en los estados de México, Distrito Federal, Puebla, Veracruz y Oaxaca, además de poblaciones de las porciones elevadas del oeste de Guatemala. La especie presenta variación en el tamaño de la planta, espaciamiento de las hojas y número de flores por tallo, debidas a las condiciones microambientales en que se desarrolla (Pringle, 1977). Las hojas varían usualmente de lanceoladas en las áreas del centro de México, a elípticas en las poblaciones de Oaxaca y Veracruz.

La subespecie michoacana presenta como características distintivas los tallos delgados, las hojas ampliamente elípticas a ovadas y los lóbulos del cáliz extendidos, anchamente elípticos a ovados. Se asemeja asimismo a G. chazaroi lltis, conocida de Durango (Iltis, 1994), de la que difiere, sin embargo, en sus flores notablemente más grandes. Una comparación más detallada de la nueva subespecie con los taxa relacionados se presenta en el Cuadro 1.

Cuadro 1. Comparación de algunos caracteres de tres taxa relacionados de Gentiana.

\begin{tabular}{|c|c|c|c|}
\hline Carácter & $\begin{array}{c}\text { G. ovatiloba } \\
\text { ssp. michoacana }\end{array}$ & $\begin{array}{l}\text { G. ovatiloba } \\
\text { ssp. ovatiloba }\end{array}$ & G. chazaroi \\
\hline Grosor del tallo & $1.0-1.2 \mathrm{~mm}$ & $1.5-2.0 \mathrm{~mm}$ & $1.5-2.0 \mathrm{~mm}$ \\
\hline Forma de la hoja & $\begin{array}{c}\text { ampliamente elíptica } \\
\text { a ovada }\end{array}$ & $\begin{array}{l}\text { lanceolada } \\
\text { a elíptica }\end{array}$ & $\begin{array}{l}\text { elíptico-ovada } \\
\text { a espatulada }\end{array}$ \\
\hline $\begin{array}{l}\text { Proporción largo/ } \\
\text { ancho de la hoja }\end{array}$ & $1.2-1.6$ & $2.5-6$ & $1-3$ \\
\hline Base de la hoja & redondeada & redondeada & atenuada \\
\hline Textura de la hoja & delgada & gruesa-suculenta & gruesa-suculenta \\
\hline
\end{tabular}


Cuadro 1. Continuación.

\begin{tabular}{|l|c|c|c|}
\hline \multicolumn{1}{|c|}{ Carácter } & $\begin{array}{c}\text { G. ovatiloba } \\
\text { ssp. michoacana }\end{array}$ & $\begin{array}{c}\text { G. ovatiloba } \\
\text { ssp. ovatiloba }\end{array}$ & G. chazaroi \\
\hline $\begin{array}{l}\text { Forma de los lóbulos } \\
\text { del cáliz }\end{array}$ & $\begin{array}{c}\text { ampliamente } \\
\text { elípticos a ovados }\end{array}$ & $\begin{array}{c}\text { lanceolados a estre- } \\
\text { chamente elípticos }\end{array}$ & $\begin{array}{c}\text { lanceolados a estre- } \\
\text { chamente elípticos }\end{array}$ \\
$\begin{array}{l}\text { Ancho de los lóbulos } \\
\text { del cáliz }\end{array}$ & $3-4 \mathrm{~mm}$ & $1-2 \mathrm{~mm}$ & $0.6-1.5 \mathrm{~mm}$ \\
$\begin{array}{l}\text { Posición de los lóbu- } \\
\text { los del cáliz }\end{array}$ & extendidos & erectos & $1.2-1.9 \mathrm{~cm}$ \\
$\begin{array}{l}\text { Largo de la corola } \\
\text { Largo de los lóbulos } \\
\text { de la corola }\end{array}$ & $2.5-3 \mathrm{~cm}$ & $2.5-4.5 \mathrm{~cm}$ & $6-7 \mathrm{~mm}$ \\
\hline
\end{tabular}

G. ovatiloba está formada por una serie de poblaciones de plantas subalpinas que crecen a 3100-3900 m s.n.m. en pastizales en medio de bosque de coníferas. La nueva subespecie representa el extremo occidental del área conocida de este complejo, sólo colectada hasta ahora del Cerro San Andrés, aislada del resto de las poblaciones de la especie.

\section{AGRADECIMIENTOS}

Se agradece al Dr. Jerzy Rzedowski por la revisión del manuscrito y la diagnosis en latín, así como a los revisores anónimos por enriquecer la presentación del artículo. La ilustración es obra del señor Cuauhtémoc González de León.

\section{LITERATURA CITADA}

Iltis, H. H. 1994. Gentiana chazaroi (Gentianaceae), a new western Mexican species. Acta Bot. Mex. 26: $1-5$.

Pringle, J. S. 1977. Taxonomy and distribution of Gentiana (Gentianaceae) in México and Central America. I Sect. Pneumonanthe. Sida 7: 174-217. 